\title{
Sleep length and quality, sleepiness and urinary melatonin among healthy Danish nurses with shift work during work and leisure time
}

\author{
Anne Helene Garde • Åse Marie Hansen • \\ Johnni Hansen
}

Published online: 28 July 2009

(C) Springer-Verlag 2009

Erratum to: Int Arch Occup Environ Health

DOI 10.1007/s00420-009-0419-4

In Figure 1, in the above paper, there was an error in the caption text. The text should read as below:

Figure 1. Diurnal profiles of sleepiness and 6-sulfatoxymelatonin among nurses with different types of shift. Solid square KSS on a workday (solid line), open square KSS on a day off (solid line), solid triangle 6-sulfatoxy-melatonin on a workday (dashed line), open triangle 6-sulfatoxy-melatonin on a day off (dashed line)

The online version of the original article can be found under doi:10.1007/s00420-009-0419-4.

A. H. Garde $(\varangle)$ A A. M. Hansen

National Research Centre for the Working Environment,

Lersø Parkallé 105, 2100 Copenhagen, Denmark

e-mail: ahg@nrcwe.dk

J. Hansen

Institute of Cancer Epidemiology,

Danish Cancer Society, Copenhagen, Denmark 